\title{
Birth outcomes among laboring mothers in selected health facilities of North Wollo Zone, Northeast Ethiopia: A facility based cross-sectional study
}

\author{
Asmamaw Eshete ${ }^{1}$, Dereje Birhanu ${ }^{2 *}$, Belaynew Wassie ${ }^{3,4}$ \\ ${ }^{1}$ Research \& Training Institute, John Snow Inc. (JSI), Bahir Dar, Ethiopia \\ ${ }^{2}$ Department of Public Health, College of Medicine and Health Science, Bahir Dar University, Bahir Dar, Ethiopia; \\ *Corresponding Author: firedereje@gmail.com \\ ${ }^{3}$ Department of Public Health, Bahir Dar University, Bahir Dar, Ethiopia \\ ${ }^{4}$ Amhara Health Bureau, Bahir Dar, Ethiopia
}

Received 10 May 2013; revised 11 June 2013; accepted 30 June 2013

Copyright (C) 2013 Asmamaw Eshete, Dereje Birhanu and Belaynew Wassie. This is an open access article distributed under the Creative Commons Attribution License, which permits unrestricted use, distribution, and reproduction in any medium, provided the original work is properly cited.

\section{ABSTRACT}

Background: Poor birth outcomes are common health problems everywhere in the world. Hence institutional delivery in Ethiopia is very low, improving birth outcomes through recent evidence remained critical. The objective of the study was to determine the prevalence of poor birth outcomes and associated factors among women who delivered in selected health facilities of North Wollo Zone. Methods: A facility based cross-sectional survey was conducted on 295 laboring mothers from May to June 2009. Interviewer administered questionnaire was used to collect the data. Patient's chart was reviewed to retrieve medical information. Anthropometry of the neonate was taken by standard measurement tools. Data were analyzed using statistical package for social sciences (SPSS), version 15. Binary logistic regression analyses were used to identify predictors of poor birth outcomes. P-value $\leq \mathbf{0 . 0 5}$ was considered statistically significant. Results: All the data resulted from 295 laboring mothers were made part of the analyses. A total of $266(\mathbf{9 0 . 2 \% )}$ laboring mothers gave live birth. A quarter, $68(23.1 \%)$ of the laboring mothers had a poor birth outcome. The common adverse outcomes were intrauterine fetal death (IUFD, preterm, and birth defects with the proportion of $29(42.6 \%), 22(32.4 \%)$, and 3 (4.4\%), respectively). Mother whose husband's occupation was merchant $(A O R=4.4,95 \% \mathrm{Cl}$ : 1.0 - 19.0), driver $(A O R=4.2,95 \% \mathrm{Cl}: 1.12$ -
15.76), \& women who were illiterate $(A O R=4.0$, 95\% Cl: $1.2-13.5)$, primary school completed $(A O R=4.3,95 \% \mathrm{Cl}: 1.3-13.8)$, non-antenatal care visited $(A O R=3.4,95 \% \mathrm{Cl}: 1.12-10.2)$, rural residence, $(A O R=2.6,95 \% \mathrm{Cl}: 1.11-5.80), \&$ mother's HIV status, (AOR $=34.2,95 \%$ CL 5.6, 207.0) were independent predictors of poor birth outcomes. Conclusions: Poor birth outcomes were very common in the study area where low birth weight accounted for much of all adverse pregnancy outcomes. Occupation, residence, antenatal care visit, income, maternal education and HIV status were determinants of poor birth outcomes. Accessing antenatal care in early trimester, mild physical work, maternal education to secondary level and above should be encouraged.

Keywords: Birth Outcome; Low Birth Weight; Laboring Mother; North Wollo; Ethiopia

\section{INTRODUCTION}

Adverse birth outcomes such as stillbirth, low birth weight and preterm birth constituted the highest rates of all the adverse pregnancy outcomes and are common in developing countries [1].

Among 136 million babies born every year, approximately 4 million are stillborn, and the other 4 million die in the first month of life. Currently around the world, $12 \%$ of babies are born prematurely, $8 \%$ with low birth weight, and 3\% have major birth defects. Adverse pregnancy outcomes lead to serious health consequences to the mother and/or the baby $[2,3]$. 
Nutrition is important in reproduction, including the safe delivery of infants. Of 20 million infants' found worldwide, 17 percent of them are found in developing countries. LBW (weight less than $2500 \mathrm{gm}$ ) increases the risk of infant mortality, which may lead to problems in child development, it also increases the risk for certain adulthood chronic disorders [4].

Obstetric complications are the major sources of stillbirths and early neonatal deaths, perhaps responsible for greater than 50 percent of such outcomes [5].

In Ethiopia, reports indicated that the caloric intake of poor women was less than $70 \%$ of the recommended, and the birth weight gained during pregnancy were significantly lower [6]. In Ethiopia, 27 percent of reproductive age women were found chronically malnourished (BMI less than $18.5 \mathrm{Kg} / \mathrm{M}^{2}$ ). Marked variation was observed among residents, where 28 percent of rural women and 19 percent of urban women were in chronic energy deficiency (BMI less than $18.5 \mathrm{~kg} / \mathrm{m}^{2}$ ) [7].

Under-nutrition is a state where physical functions of an individual are impaired to the point where she/he can no longer maintain an adequate level of performance on physical work, recovering from effects of disease, maintaining adequate level of growth, or the process of pregnancy or lactation. Maintaining an optimal nutrition to pregnant mother is therefore a sensitive indicator to estimate the health status and nourishment levels of a population [8].

Birth weight is also an important determinant of perinatal, neonatal and post neonatal outcomes. Poor intra-uterine growth would increase the risks of perinatal, infant and child mortality and morbidity. Consequently, addressing the burden of low birth weight would contribute significantly towards the achievement of Millennium Development Goals especially Goal 4. Globally the incidence rate of Low Birth Weight is $15.5 \%$, Africa has an incidence of $14.3 \%$, double than the incidence of the developed world $(7 \%)[9,10]$.

The effects of poverty on pregnancy are too complex and could increase the risk of both preterm and IUGR. Mothers who were not attending antenatal care either due to lack of money or inaccessibility, long working hours, less knowledge/education on how to use the service, close family spacing, and maternal age, have shown increased risk on preterm delivery, low birth weight or still birth. In Ethiopia, based on maternal estimates, $37.7 \%$ \& $33.4 \%$ of children born to teenage \& adult mothers respectively were below average sizes at birth [11-13].

The World Health Organization (WHO) estimated that an average of $56 \%$ of pregnant women in developing countries is anemic, much higher than the $18 \%$ of anemic pregnant women in developed countries [14].

Despite the fact that birth outcomes worldwide have im- proved dramatically in the past 40 years, the gaps in developing countries are widening. Studies on maternal nutrition andbirth outcomes have been done so limited in our country and none in the study area. Therefore, the study aimed to assess the proportion of birth outcomes and associated factors among women who delivered in selected health facilities of North Wollo Zone, Northeast Ethiopia.

\section{METHODS}

\subsection{Study Design}

Facility based cross-sectional survey was conducted to assess the proportion of poor birth outcomes and associated factors among laboring mothers. The study was conducted from May to June 2009 in the selected health facilities of North Wollo Zone.

\subsection{Study Area and Settings}

North Wollo zone is found $521 \mathrm{Km}$ away from Addis Ababa, the capital city of Ethiopia. The zone has 3 urban and 10 rural districts. From the total 1,664,586 estimated population, about 1,499,395 were rural dwellers. From the total population, 49.9 percent were females. Reproductive age women accounted for about 23 percent. According to 2009 Zonal Health office report, there were 2 Zonal/District Hospitals, and 20 Health Centers. The potential health care coverage of the zone was $96.9 \%$.

\subsection{Source and Study Population}

The source populations were all pregnant women in North Wollow Zone and the study populations were laboring mothers who came to the randomly selected health institutions for delivery services during the study period. All laboring mothers who gave birth in the selected health institutions or those who came to the health institution within 24 hours after home delivery for postnatal and/or neonatal care services were included in the study.

\subsection{Sample Size Determination \& Sampling Procedures}

Single population proportion formula $\mathrm{n}=\mathrm{Z} 2 * \mathrm{P}(1-$ $\mathrm{P}) / \mathrm{d} 2$, where $\mathrm{n}=$ estimated sample size, $\mathrm{Z}=$ confidence level $(95 \%), \mathrm{P}=$ proportion of poor birth outcomes (proportion of LBW i.e. $22.5 \%$, [15] \& d = margin of error $(5 \%)$ ), was used to determine the required sample size. Using the above formula, the required sample size was 268 , and by adding $10 \%$ non-response rate, the final sample size required was 295. In the zone there were 2 hospitals and 20 health centers owned by Government. From the list of health facilities, one hospital and four health centers 
were selected randomly using lottery method. According to the Zonal Health Department report, in Woldiya Zonal Hospital about $100-120$ mothers and in each selected health centers, about 30 - 40 mothers were delivered per month. All mothers who came to the selected health institutions and fulfilled the inclusion criteria were included in the study until the required sample size was reached.

\subsection{Data Collection Procedure}

Interviewer administered questionnaire was used to collect the data. Anthropometric measurements were also taken to estimate the nutritional status of mothers. We also reviewed client's chart to retrieve medical information and mother's test results that could not be captured by the interview. Clinical assessments, chart review, interview, and anthropometric measurements were taken after delivery when the woman who was considered both physiologically and physically well/stable. All the data collection was carried from May-June, 2009.

\subsection{Measurements}

Mid-upper arm circumference was taken from the mothers' left extended \& relaxed arm just at the midpoint of the tip of shoulder girdle and elbow using Shakir strip tape.

Height of the mother: The height of the mother was taken by using studio meter in standing and the head in the Frankfurt position with her occipit, shoulders, buttocks, \& her bare foot heel touched the vertical stand using a fixed (marked by 0.5 centimeter) intervals in the post laboring ward after delivery.

Baby weight: The weight of a naked neonate was taken right after birth and/or within 24 hours after home delivery using ordinary baby weight scale.

Chest circumference: The circumference of the neonate's chest was measured taking his/her nipple as a land mark through the back of thoracic cavity using a fixed non-stretchable measuring tape graduated at $0.5 \mathrm{~cm}$ interval.

Last normal menstrual period (LNMP) was confirmed both from her chart, and through interview. Gestational age was estimated based on her LNMP, using Ultrasound report from chart review.

\subsection{Operational Definitions}

Poor birth outcome: a mother who gave severely asphyxiated or preterm or IUFD, or a baby with visible birth defects.

Low birth weight: a baby whose chest circumference was less than $29.00 \mathrm{~cm}$ or weighting less than $2500 \mathrm{gms}$.

Physical work done: a mother who engaged on ag- ricultural activities or fetching water for more than 15 minutes walks, or hand grinding during the current pregnancy.

Severely asphyxiated: a baby with APGAR scores of $\leq 3$ out of ten in the 1 st minute after delivery.

\subsection{Data Quality Control}

To maintain the quality of data, the questionnaire was pre-tested and amended accordingly. Training including practical demonstration was given to data collectors and supervisors. There was close supervision of data collectors by the supervisors and investigators. The weight measurement instrument was checked before and after each baby was measured and a non-stretchable graduated measuring tape was used to measure the height of the mother.

\subsection{Data Processing and Analyses}

The data was checked, cleaned, and entered on the SPSS Version 15, statistical software. Descriptive statistics were computed to determine the proportion of poor birth outcomes, \& mother's socio-demographic characteristics. Logistic regression analyses were used to identify independent predictors of poor birth outcomes. Pvalue $\leq 0.05$ was considered as statistically significant. Odds ratio was used to determine the strength of association between independent variables and the birth outcomes

\subsection{Ethical Considerations}

Ethical clearance was obtained from the ethical review board of School of Public Health, University of Gondar. Permission was obtained from North Wollo Zonal Health Department, and from all the selected health centers after the objectives of the study was explained. Informed consent was obtained from each participant. Participants were also told they are liberal to withdraw at any time and/or not to respond to any of the items whenever they don't want to answer. Participants were also informed that all the data obtained from them would be kept confidential using codes instead of any personal identifiers. Psychosocial support, treatment, and health education was given for mothers who gave still birth, IUFD, preterm and/or low birth weight babies.

\section{RESULT}

\subsection{Participants' Demographic and Socio-Economic Characteristics}

A total of 295 mothers were interviewed, of which $80 \%$ were in the age group 20 - 34 years. More than $90 \%$ were married, and $46.4 \%$ were rural dwellers. One hun- 
dred twelve participants $(38.0 \%)$ were house wives, and in $75(25.4 \%)$ of participants, the family monthly income was less than 300.00 Eth Birr (20 USD Dollar) (Table 1).

Table 1. Demographic \& socioeconomic characteristics of participants $(n=295)$ North Wollo Zone from May-June, 2009.

\begin{tabular}{|c|c|c|}
\hline Characteristics & Frequency & Percent \\
\hline \multicolumn{3}{|l|}{ Age at delivery } \\
\hline$<20 \mathrm{yr}$ & 31 & 10.5 \\
\hline $20-34 \mathrm{yr}$ & 237 & 80.3 \\
\hline $35-49 \mathrm{yr}$ & 27 & 9.2 \\
\hline \multicolumn{3}{|l|}{ Marital status } \\
\hline Married & 274 & 92.9 \\
\hline Single & 15 & 5.1 \\
\hline Divorced/separated & 6 & 2.1 \\
\hline \multicolumn{3}{|l|}{ Religion } \\
\hline Orthodox & 222 & 75.3 \\
\hline Muslim & 73 & 24.7 \\
\hline \multicolumn{3}{|l|}{ Residence } \\
\hline Urban & 158 & 53.6 \\
\hline Rural & 137 & 46.4 \\
\hline \multicolumn{3}{|l|}{ Maternal education } \\
\hline Sec. \& higher & 112 & 38.0 \\
\hline Primary & 98 & 33.2 \\
\hline Illiterate & 85 & 8.8 \\
\hline \multicolumn{3}{|l|}{ Maternal Occupation } \\
\hline Gov’t employed & 58 & 19.7 \\
\hline House wife & 112 & 38.0 \\
\hline Farmer & 78 & 26.4 \\
\hline Merchant & 30 & 0.2 \\
\hline Housemaid & 17 & 5.8 \\
\hline \multicolumn{3}{|l|}{ Husband occupation } \\
\hline Gov't employed & 89 & 30.2 \\
\hline Daily laborer & 17 & 5.8 \\
\hline Farmer & 88 & 29.8 \\
\hline Merchant & 49 & 16.6 \\
\hline Soldier & 19 & 6.4 \\
\hline Driver & 33 & 1.2 \\
\hline \multicolumn{3}{|l|}{ Husband education } \\
\hline Sec \& higher & 137 & 46.4 \\
\hline Primary & 89 & 30.2 \\
\hline Illiterate & 69 & 23.4 \\
\hline \multicolumn{3}{|l|}{ Monthly family income } \\
\hline$\leq 300$ Birr & 75 & 25.4 \\
\hline $301-1000$ Birr & 116 & 39.3 \\
\hline$\geq 1001$ Birr & 104 & 35.3 \\
\hline
\end{tabular}

\subsection{Nutritional Status and Substance Uses of Laboring Mothers}

From the total 295 mothers, 39 (13.3\%) had height $\leq 149 \mathrm{cms}$. During their current pregnancy, about $5 \%$ of participants reported they suffered from night blindness. More than one third of participants had anterior neck mass \& nearly $3 / 4$ th of mother's MUAC was below 23.5 $\mathrm{cm}$. From the total participants 13 (4.4\%), 166 (56.3\%), and $266(90.2 \%)$ had respectively chewed "khat" and/or smoked "Shisha", drunk alcohol (e.g. "Tela" \& "Tej"); had used caffeine containing foods either daily, weekly, or occasionally during their current pregnancy (Table 2).

\subsection{Obstetric/Gynecologic Characteristics of Laboring Mothers}

From the total 295 laboring mothers, about one fifth of them were delivered by caesarean section. Almost in $95 \%$ of mothers, the birth space between the previous and the current pregnancy was 24 months or more. More than four fifth (86.5\%) of mothers had 4 or more children and the same proportion of mothers were circumcised. From mothers whose birth interval was 18 months or more, $30(10.2 \%)$ had poor birth outcomes (Table 3).

\subsection{Regarding to the Birth Outcomes}

More than $90 \%$ of neonates were live births, and from the total live births, $34(12.8 \%)$ were LBW, and three babies were with visible birth defect.

From the total births, $81(27.5 \%)$ were with poor birth outcomes. More than three fourth of the babies born were non-asphyxiated in the 1st and 5th minutes after delivery. Nearly $85 \%$ of laboring mothers were at term by gestation (Table 4).

\subsection{Associated Factors for Poor Birth Outcomes}

Mothers whose husband was merchant or driver were more than 4 times to have poor birth outcome than mothers whose husband were government employed $(\mathrm{AOR}=4.4,95 \% \mathrm{CI}[1.0,19.0], \mathrm{AOR}=4.2,95 \% \mathrm{CI}$ $[1.12,15.76])$ respectively. Mothers who didn't attend ANC were more than 3 times to have poor birth outcome, than mothers who attended ANC follow up, $\mathrm{AOR}=3.4$, $95 \%$ CI $[1.12,10.2]$. Mothers who were illiterate, who were at primary education level were 4 times more likely to have poor birth outcome than those who had secondary education level and more, $\mathrm{AOR}=4.3,95 \% \mathrm{CI}[1.3$, 13.8], $\mathrm{AOR}=4.0,95 \%$ CI $[1.2,13.5]$ respectively. Mothers who lived in rural area encountered poor birth outcomes more than two times than mothers who lived in urban area, AOR $=2.6,95 \%$ CI $[1.11,5.8]$. Mothers whose occupation was house wife, farmer, merchant and 
Table 2. Nutritional status and substance uses of laboring mothers, North Wollo Zone May-June, 2009.

\begin{tabular}{|c|c|c|}
\hline Characteristics & Frequency & Percent \\
\hline \multicolumn{3}{|l|}{ MUAC $^{*}$} \\
\hline$>23.5 \mathrm{~cm}$ & 76 & 25.8 \\
\hline $21.00-23.50 \mathrm{~cm}$ & 169 & 57.3 \\
\hline$<21.00 \mathrm{~cm}$ & 50 & 16.9 \\
\hline \multicolumn{3}{|l|}{ Height } \\
\hline$\geq 155 \mathrm{~cm}$ & 193 & 65.4 \\
\hline $150-154 \mathrm{~cm}$ & 63 & 21.4 \\
\hline $145-149 \mathrm{~cm}$ & 30 & 10.2 \\
\hline$<145 \mathrm{~cm}$ & 9 & 3.1 \\
\hline \multicolumn{3}{|l|}{ Goiter grade $^{*}$} \\
\hline Grade I & 183 & 62.0 \\
\hline Grade II & 87 & 29.5 \\
\hline Grade III & 25 & 8.5 \\
\hline \multicolumn{3}{|l|}{ Hgb level, $(n=68)$} \\
\hline Normal & 57 & 83.8 \\
\hline Anemia & 11 & 16.2 \\
\hline \multicolumn{3}{|c|}{ Night blinding (“dafint") } \\
\hline Not occurred & 281 & 95.3 \\
\hline Occurred & 14 & 4.7 \\
\hline \multicolumn{3}{|l|}{ Khat and Shisha use } \\
\hline Never & 282 & 95.6 \\
\hline Daily & 4 & 1.4 \\
\hline Weekly & 1 & 0.3 \\
\hline Occasionally & 8 & 2.7 \\
\hline \multicolumn{3}{|l|}{ Alcohol uses ${ }^{*}$} \\
\hline Never & 129 & 43.7 \\
\hline Daily & 15 & 5.1 \\
\hline Weekly & 28 & 9.5 \\
\hline Occasionally & 123 & 41.7 \\
\hline \multicolumn{3}{|l|}{ Caffeine uses ${ }^{* *}$} \\
\hline Never & 29 & 9.8 \\
\hline Daily & 68 & 23.1 \\
\hline Weekly & 125 & 42.4 \\
\hline Occasionally & 73 & 24.7 \\
\hline
\end{tabular}

*Grade I, if thyroid gland is neither visible nor palpable; Grade II, if the gland was palpable but not visible; Grade III, if the gland was grossly visible $\&$ palpable (WHO thyroid size category) ${ }^{* *}$ caffeine $=$ coffee $\&$ coca-cola.

those who were working $4-8 \mathrm{hr} /$ day while they were pregnant were $90 \%, 80 \%, 87 \%$, and $70 \%$ less likely to have poor birth outcome than their counters respectively (Table 5).

\subsection{Associated Factors for Newborn Birth Weight}

Low birth weight was the major public health prob-
Table 3. Obstetric and gynecologic characteristics of laboring mothers in North Wollo Zone, from May-June 2009.

\begin{tabular}{|c|c|c|}
\hline Characteristics & Frequency & Percent \\
\hline \multicolumn{3}{|l|}{ Mode of delivery } \\
\hline Spontaneous & 210 & 71.2 \\
\hline Instrument assisted & 29 & 9.8 \\
\hline $\mathrm{C} / \mathrm{S}$ & 56 & 19 \\
\hline \multicolumn{3}{|l|}{ Birth interval } \\
\hline 12 - 23 months & 10 & 6.3 \\
\hline $24-47$ months & 69 & 43.4 \\
\hline$\geq 48$ months & 80 & 50.3 \\
\hline \multicolumn{3}{|l|}{ Parity } \\
\hline 1 & 13 & 4.4 \\
\hline $2-3$ & 27 & 9.2 \\
\hline $4-5$ & 107 & 36.3 \\
\hline$\geq 6$ & 148 & 50.2 \\
\hline \multicolumn{3}{|l|}{ Hx of prolonged labor } \\
\hline Yes & 16 & 5.4 \\
\hline No & 279 & 94.6 \\
\hline \multicolumn{3}{|l|}{ LBW delivery Hx } \\
\hline Yes & 2 & 0.7 \\
\hline No & 293 & 99.3 \\
\hline \multicolumn{3}{|l|}{ Preterm delivery before } \\
\hline Yes & 3 & 1.0 \\
\hline No & 292 & 99.0 \\
\hline \multicolumn{3}{|l|}{ Previous stillbirth } \\
\hline Yes & 24 & 8.1 \\
\hline No & 271 & 91.9 \\
\hline \multicolumn{3}{|l|}{ History of abortion } \\
\hline Yes & 33 & 11.2 \\
\hline No & 262 & 88.8 \\
\hline \multicolumn{3}{|l|}{ Circumcision history } \\
\hline Yes & 254 & 86.1 \\
\hline No & 41 & 13.9 \\
\hline
\end{tabular}

lems in the world; therefore the study was framed to investigate the associated risk factors to the occurrence of low birth weight. Monthly family income, marital status, and HIV status were the predictors to deliver low birth weight baby than their counterparts, $A O R=19.6,95 \%$ CL (1.6, 243.03), AOR $=10.5,95 \%$ CL (1.5, 75.3), AOR $=34.2,95 \%$ CL $(5.6,207.0)$ respectively. Mothers who had no history of UTI and/or any documentation for bacteriuria during the current pregnancy were $90 \%$ less likely to deliver low birth weight baby than mothers who had urinary tract infection, AOR $=0.1,95 \%$ CI $(0.02$, 0.36) (Table 6). 
Table 4. Birth outcomes of laboring mothers in North Wollo Zone, Northeast Ethiopia, from May-June 2009.

\begin{tabular}{lcc}
\hline Outcome & Frequency & Percent \\
\hline Status of neonate at birth & 266 & 90.2 \\
$\quad$ Alive & 29 & 9.8 \\
IUFD & & \\
APGAR score at 1st minute & 224 & 75.9 \\
$\quad$ No asphyxia & 44 & 14.9 \\
Moderate asphyxia & 27 & 9.2 \\
Severe asphyxia & & \\
APGAR score at 5 th minute & 262 & 88.8 \\
$\quad$ No asphyxia & 4 & 1.4 \\
Moderate asphyxia & 29 & 9.8 \\
Severe asphyxia & & \\
Gestational age & 250 & 84.7 \\
Term & 22 & 7.5 \\
Preterm & 23 & 7.8 \\
Post term & & \\
Birth weight of live births $(\mathrm{n}=266)$ & 227 & 85.3 \\
Normal $(2.50-4.00 \mathrm{~kg})$ & 34 & 12.8 \\
LBW $(<2.50 \mathrm{~kg})$ & 5 & 1.9 \\
Macrosomia $(>4.00 \mathrm{~kg})$ & & \\
Visible birth defect & 292 & \\
Yes & & \\
No & & \\
\hline & & \\
\hline
\end{tabular}

\section{DISCUSSION}

Birth outcomes such as IUFD, low birth weight, and still birth are public concerns throughout the world. Developing countries were with the highest rates of these adverse birth outcomes. From the total 295 participants, $81(27.5 \%)$ had faced poor birth outcomes, of which 29 (35.8\%) were IUFD; 27 (33.3\%) were severally asphyxiated, and $22(27.2 \%)$ were preterm births. From the total live births, 34 (12.8\%) were born low birth weight. These finding is in contradiction with a study done in US where $12 \%$ of babies born were premature, $8 \%$ were LBW, and $3 \%$ were with major birth defects [3]. The higher proportion of poor birth outcomes in this study may be due to the difference in socio-economic status, low service accessibility; poor knowledge on pregnancy risks and related services, even the difference could be due to the tradition of the two extreme populations.

It is agreed that focused ANC service utilization resulted in reducing maternal and neonatal morbidity and mortality by early detecting the health risks/diseases women were suffering from, and by counseling mothers what to do while she is pregnant. In this study, women who didn't attend ANC encountered poor birth outcomes than ANC attendant mothers. This could be due to the fact that mothers who attend ANC could get advice, early diagnosis and treatment and also to have early referral to the appropriate health facility if needed. The finding is in agreement with a study done in Jimma hospital [15] and Metu Karl hospital [16].

In this study, rural residence was an independent predictor for poor birth outcome such as LBW. The finding is consistent with a study done in Gambia [17]. But was not consistent with a study done in Jimma hospital and adjacent health institutions, where urban setting was independent predictor for LBW [15]. This is may be due to the difference in the definition of residence (urban and rural), or the urban people living in Jimma might have culture or tradition such as food taboos and other practices which could affect the nutritional status of the mother, and also in our study weight measurements was not taken for IUFDs which could be from urban dweller mothers.

Based on this study, the odds of facing poor birth outcomes was $70 \%$ lesser among mothers who were engaged on physical work daily for $4-8$ hours during their pregnancy as compared to those mothers who were not engaged on work at all. UNCIF/WHO reported that physically demanding work during pregnancy contributed to poor fetal growth [9]. Although, the operational definition of type of work would vary, mild work/exercise could help the mother in improving her appetite so could consume well or such an activity would increase her fitness so that would cope challenges during child birth.

In this study mothers who were house wife, farmer, or merchant were $90 \%, 80 \%$, and $87 \%$ less likely to have poor birth outcomes than those who were government employee respectively. This could be possibly due to mild physical activity/work which is thought to be good for healthy life. Therefore mothers who were farmers could benefit from such an activity. House wives might have enough time to take care for themselves \& to have adequate rest. Merchant mothers may have better financial freedom and access so could consume balanced diet. Therefore all these conditions could help the mother to have good birth outcomes than government employees. On the contrary, husbands' occupation (being merchant, or driver) was the risk factor for poor birth outcome. Possibly due to nature of the occupation where in our culture if her husband is not around home, wives usually didn't prepare food properly so that might not consume nutritious diet and even she might not visit health institutions for maternity services that could lead the mother to have economic \& psychosocial problems leading her to infection or malnutrition.

According to this study, the proportion of LBW was $11.5 \%$ and was consistent to in a study done in Jimma hospital $(11.02 \%)$ [15]. It was less as compared to the 
Table 5. Associated risk factors for birth outcome among laboring mothers $(\mathrm{n}=295)$ in North Wollo Zone, from May-June, 2009.

\begin{tabular}{|c|c|c|c|c|c|}
\hline \multicolumn{2}{|c|}{ Variables/Response } & \multicolumn{2}{|c|}{ Birth outcome } & \multicolumn{2}{|c|}{ OR (95\% CI) } \\
\hline & & Good & Poor & COR & AOR \\
\hline \multirow{3}{*}{$\begin{array}{c}\text { Income of the } \\
\text { family }\end{array}$} & $\geq 1001$ Birr (Ref) & 91 & 13 & 1 & 1 \\
\hline & $301-1000$ Birr & 91 & 25 & $1.9(0.93,3.99)$ & $1.1[0.40,3.03]$ \\
\hline & $\leq 300$ Birr & 45 & 30 & $4.7(2.22,9.80)$ & $2.6[0.8,8.13]$ \\
\hline \multirow{6}{*}{$\begin{array}{c}\text { Father } \\
\text { occupation }\end{array}$} & Gov’t employed (Ref.) & 79 & 10 & 1 & 1 \\
\hline & Daily laborer & 14 & 3 & $1.7(0.41,6.93)$ & $2.3[0.33,16.1]$ \\
\hline & Farmer & 56 & 32 & $4.5(2.05,9.93)$ & $3.7[0.79,17.01]$ \\
\hline & Merchant & 39 & 10 & $2.0(0.78,5.27)$ & $4.4[1.0,19.0]$ \\
\hline & Soldier & 15 & 4 & $2.1(0.60,7.60)$ & $3.2[0.5,20.6]$ \\
\hline & Driver & 24 & 9 & $3.0(1.08,8.13)$ & $4.2[1.12,15.76]$ \\
\hline \multirow{5}{*}{$\begin{array}{l}\text { Mother } \\
\text { Occupation }\end{array}$} & Gov't employed (Ref). & 47 & 11 & 1 & 1 \\
\hline & House wife & 93 & 19 & $0.9(0.4,1.98)$ & $0.1[0.03,0.47]$ \\
\hline & Farmer & 50 & 28 & $2.4(1.1,5.34)$ & $0.2[0.02,0.86]$ \\
\hline & Merchant & 26 & 4 & $0.7(0.2,2.3)$ & $0.13[0.02,0.93]$ \\
\hline & Housemaid & 11 & 6 & $2.3(0.71,7.7)$ & $0.4[0.06,2.2]$ \\
\hline \multirow{4}{*}{ ANC visit } & 1st trimester (Ref.) & 68 & 15 & 1 & 1 \\
\hline & 2nd trimester & 99 & 24 & $1.1(0.54,2.25)$ & $1.1[0.4,2.4]$ \\
\hline & 3rd trimester & 44 & 9 & $0.9(0.4,2.3)$ & $0.8[0.26,2.2]$ \\
\hline & No ANC visit & 16 & 20 & $5.7(2.4,13.4)$ & $3.4[1.12,10.2]$ \\
\hline \multirow{4}{*}{$\begin{array}{l}\text { Physical work } \\
\text { duration }\end{array}$} & Not done (Ref.) & 154 & 38 & 1 & 1 \\
\hline & $<4 \mathrm{hr}$ & 34 & 17 & $2.0(1.03,4.01)$ & $0.9[0.37,2.2]$ \\
\hline & $4-8 \mathrm{hr}$ & 29 & 9 & $1.3(0.55,2.87)$ & $0.3[0.1,0.78]$ \\
\hline & $>8 \mathrm{hr}$ & 10 & 4 & $1.6(0.48,5.45)$ & $0.3[0.06,1.27]$ \\
\hline \multirow{3}{*}{ MUAC } & $>23.5 \mathrm{~cm}$ (Ref.) & 61 & 15 & 1 & 1 \\
\hline & $21.00-23.50 \mathrm{~cm}$ & 134 & 35 & $1.1(.54,2.09)$ & $0.7[0.28,1.55]$ \\
\hline & $<21.00 \mathrm{~cm}$ & 32 & 18 & $2.3(1.02,5.13)$ & $1.5[0.5,4.03]$ \\
\hline \multirow{3}{*}{$\begin{array}{l}\text { Mother's } \\
\text { education }\end{array}$} & Sec \& higher (Ref.) & 16 & 21 & 1 & 1 \\
\hline & Primary & 68 & 21 & $3.1(1.48,6.29)$ & $4.3[1.3,13.8]$ \\
\hline & Illiterate & 43 & 26 & $3.5(1.69,7.40)$ & $4.0[1.2,13.5]$ \\
\hline \multirow{2}{*}{ Residence } & Urban (Ref.) & 134 & 24 & 1 & 1 \\
\hline & Rural & 93 & 44 & $2.6(1.5,4.64)$ & $2.6[1.11,5.8]$ \\
\hline \multirow{2}{*}{$\begin{array}{c}\text { Presence of } \\
\text { oedema }\end{array}$} & Yes & 13 & 9 & $2.5(1.02,6.16)$ & $2.6[0.82,8.2]$ \\
\hline & No (Ref.) & 214 & 59 & 1 & 1 \\
\hline \multirow{4}{*}{$\begin{array}{l}\text { Mother's } \\
\text { Height }\end{array}$} & $\geq 155 \mathrm{~cm}$ (Ref.) & 150 & 43 & 1 & 1 \\
\hline & $150-154 \mathrm{~cm}$ & 53 & 10 & $0.7(0.31,1.4)$ & $0.5[0.2,1.3]$ \\
\hline & $145-149 \mathrm{~cm}$ & 20 & 10 & $1.7(0.76,4.01)$ & $1.7[0.6,4.97]$ \\
\hline & $<145 \mathrm{~cm}$ & 4 & 5 & $4.4(1.12,16.95)$ & $2.9[0.55,15.21]$ \\
\hline
\end{tabular}


Table 6. Associated risk factors for birth weight of newborns, North Wollo, from May 13-Jun 13, 2009.

\begin{tabular}{|c|c|c|c|c|c|}
\hline \multirow{2}{*}{ Variables } & & \multicolumn{2}{|c|}{ Birth Weight } & \multicolumn{2}{|c|}{$95 \% \mathrm{CI}$} \\
\hline & & Normal & Low & COR & AOR \\
\hline \multirow{3}{*}{ Income of the family } & $\geq 1001$ Birr (Ref.) & 91 & 8 & 1 & 1 \\
\hline & $301-1000$ Birr & 91 & 10 & $7.2(0.9,59.8)$ & $8.9[0.8,103.24]$ \\
\hline & $\leq 300$ Birr & 45 & 16 & $23.3(2.95,184.2)$ & $19.6[1.6,243.03]$ \\
\hline \multirow{2}{*}{ Marital status } & Married (Ref.) & 214 & 31 & 1 & 1 \\
\hline & unmarried & 13 & 3 & $4.1[1.03,16.3]$ & $10.5[1.5,75.3]$ \\
\hline \multirow{3}{*}{ Husband education } & Sec \& higher (Ref.) & 116 & 13 & 1 & 1 \\
\hline & Primary & 68 & 13 & $3.5[1.14,10.6]$ & $1.2[0.26,5.3]$ \\
\hline & Illiterate & 43 & 8 & $2.6[0.71,9.2]$ & $0.5[0.07,2.9]$ \\
\hline \multirow{2}{*}{ Hyper emesis Hx } & Yes & 70 & 8 & $0.1[0.02,0.86]$ & $0.2[0.02,1.92]$ \\
\hline & No (Ref.) & 157 & 26 & 1 & 1 \\
\hline \multirow{3}{*}{ MUAC of the mother } & $>23.5 \mathrm{~cm}$ (Ref.) & 61 & 9 & 1 & 1 \\
\hline & $21.00-23.50 \mathrm{~cm}$ & 134 & 18 & $2.7(0.58,12.4)$ & $5.2[0.73,37.2]$ \\
\hline & $<21.00 \mathrm{~cm}$ & 32 & 7 & $7.7(1.5,39.0)$ & $6.5[0.8,54.3]$ \\
\hline \multirow{3}{*}{ HIV status } & Negative(Ref.) & 195 & 24 & 1 & 1 \\
\hline & Positive & 10 & 6 & $9.8(\mathbf{2 . 8 4}, \mathbf{3 3 . 4})$ & $34.2[5.6,207.00]$ \\
\hline & Refuse test & 22 & 4 & $5.1(1.6,16.31)$ & $5.0[1.0,25.0]$ \\
\hline \multirow{3}{*}{ Urine analysis/UTI } & Negative (Ref.) & 22 & 5 & 1 & 1 \\
\hline & Bacteria/UTI/ & 18 & 4 & $0.2(0.018,1.436)$ & $0.1[0.01,4.26]$ \\
\hline & Not done/Hx & 187 & 25 & $0.2(0.077,0.651)$ & $0.1[0.02,0.36]$ \\
\hline
\end{tabular}

globe (15.5\%), from Asian prevalence (18\%) and even from Africa as a whole (14\%) [9].

The difference could be due to the study design used, the year of study, study area included, socio cultural, health service accessibility. What so ever the difference could be, such high proportion of LBW could suggest that the rates \& even the determinants of LBW were found different across countries and nations.

In this study, marital status showed a significant effect to deliver LBW baby. Women who were not married were ten times to deliver LBW baby than married women. Women may not get married because of the health problems, or disability she had, or due to poor economic status, or may not have someone who could support her physically and psychologically so are likely to be malnourished than married women. This is consistent with a Meta-analysis study done in New Delhi India [18].

In this study mothers whose monthly family income was $<300.00$ Eth Birr were about 20 times more likely to deliver LBW baby than those whose monthly family income was $>1000.00$ Eth Birr. Mothers in deprived socioeconomic conditions frequently have low birth weight, implying that household food security should be the priority in addition to accessing reproductive health services. Similar concepts have also been documented by UNCIF and WHO reports [9].

HIV positive mothers and those who refused HIV testing (for reasons of disclosure or might already know their status or had risk behavior for HIV before) delivered LBW baby unlike HIV negative mothers. This might be due to the fact that HIV positive individuals could have high energy and other nutrient demands and might have frequent infections such as HIV that could aggravate malnutrition; therefore the nutritional status of both the mothers and their baby would be affected. This may be due to the fact that affects the socio-economic and nutritional status of the mother especial during pregnancy so that it could determine the weight of the new born. These predictive concepts have also been reported by UNCIF and WHO [9]. Similarly, a study done in Tanzania reported that HIV positive women were twice more likely to give LBW infants than HIV negative mothers [19].

Mothers with no history of UTI or urinalysis was not done during their current pregnancy were $90 \%$ less likely to give low birth weight baby. This is consistent with a Meta-analysis study done in New Delhi, India [18].

Although maternal height, alcohol, coffee consumption, parity, birth interval, and abortion history were identified as risk factors for LBW, they didn't show statistically significant association to poor birth outcomes. 


\section{CONCLUSIONS AND RECOMMENDATION}

More than a quarter of birth outcomes are Poor, among which IUFD has accounted the highest proportion.

Low birth weight, a predictor to assess maternal nutrition in intra pregnancy, is still high in the study area. Maternal education, residence, family income, HIV status, and non-ANC follow up are the major predictors for poor birth outcomes.

Availing good nutrition, timely care of HIV infected women and encouraging women's education to higher levels are vital to improve the birth outcomes. Timely and focused antenatal and neonatal care should be given due attention in the health facilities so that women and their new-born could get the necessary care that could keep them alive and in good health conditions.

\section{AUTHORS' CONTRIBUTIONS}

$\mathrm{AE}$ and $\mathrm{BW}$ designed the study. $\mathrm{AE}$ and $\mathrm{DB}$ contributed on the data collection and entry. DB drafted the manuscript. All the authors revised and approved the final manuscript.

\section{ACKNOWLEDGEMENTS}

We are highly indebted to Amhara Regional Health Bureau for sponsoring this research project. We would like to extend our thanks to North Wollo Zone Health Department Administration for permitting us to conduct the study. We would also like to extend our appreciation to Woldiya Hospital, and the selected health Center administrators for their all rounded cooperation. We also thank all study participants, data collectors, and supervisors.

\section{REFERENCES}

[1] Hornstra, G., Uauy, R. and Yang, X. (2005) The impact of maternal nutrition on the offspring. Nestlé Nutrition Workshop Series Pediatric Program, Nestec Ltd., Vevey/S. Karger AG, Basel, 1-15.

[2] Taffa, N. and Obare, F. (2004) Pregnancy and child health outcomes among adolescents in Ethiopia. The Ethiopian Journal of Health Development, 18, 90-95.

[3] Kent, H., Johnson, K., Curtis, M., Hood, J.R. and Atrash, H. (2006) Atlanta, GA: National center on birth defects \& developmental disabilities. Proceedings of the Preconception Health and Health Care Clinical, Public Health, and Consumer Workgroup Meetings, Atlanta, 27-28 June 2006, 30 p.

[4] Bale, J.R., Stoll, B.J. and Lucas, A.O. (2003) Improving birth outcomes: Meeting the challenges in the developing world. Committee on Improving Birth Outcomes, Board on Global Health, Institute of Medicine of the National Academy of Science, The National Academic Press, Washington DC, 372.

[5] M. Wiebenga (2007) "Safe Motherhood at Twenty" desk study for share-net. Public Health Consultants, Amsterdam, 1-64.

[6] Tafari, A., Naeye, R.L. and Gobezie, A. (1980) Effects of maternal under nutrition and heavy physical work during pregnancy on birth weight. British Journal of Obstetrics and Gynaecology, 87, 222-226. doi:10.1111/j.1471-0528.1980.tb04523.x

[7] Central Statistical Agency and ORC Macro (2006) Ethiopia demographic and health survey 2005. Central Statistical Agency and ICF International, Addis Ababa, Ethiopia and Calverton, Maryland.

[8] Abel, E.L. and Hunninghan, J.H. (1995) J-shaped' relationship between drinking during pregnancy \& birth weight: Reanalysis of prospective epidemiological data Alcohol, 30, 345-355.

[9] Wardlaw, T., Blanc, A., Zupan, J. and Åhman, E. (United Nations Children's Fund and World Health Organization) (2004) Low birth weight: Country, regional and global estimates. UNICEF, New York.

[10] Basso, O., Olsen, J., Knudsen, L., et al. (1998) Pregnancy within 8 months of a previous birth showed an increased risk of preterm delivery. American Journal of Obstetrics \& Gynecology, 178, 259-263.

[11] Scheirer D. and Laflamme, M. (2006) Maternal hemoglobin concentration of pregnancy outcome: A study of effects of elevation in El Alto, Bolivia. Honors Junior/Senior Projects, Paper 29.

[12] Kirchengast, S. and Hartmann, B. (2007) Short stature is associated with an increased risk of caesarean deliveries in low risk population. Acta Medica Lituanica, 14, 1-6.

[13] Sanders, D., Reynolds, L., Westwood, T., et al. (2007) Western cape burden of disease reduction project, volume 7 of 7. Decreasing the Burden of Childhood Disease Final Report, 1-4.

[14] Villar, J. and Bellizan, J.M. (1982) The relative contribution of prematurity and fetal growth retardation to low birth weight in developing and developed societies. American Journal of Obstetrics \& Gynecology, 143, 793-798.

[15] Gebremariam, A. (2005) Factors predisposing to low birth weight in Jimma Hospital South Western Ethiopia. East African Medical Journal, 82, 554-558.

[16] Nekatibeb, G. and Mariam, A. (2007) Analysis of birth weight in Metu Karl hospital South West Ethiopia. Ethiopian Medical Journal, 45, 195-202.

[17] Geenwood, A.M., Greenwood, B.M., Bradely, A.K., et al. (1987) A prospective survey of the outcome of pregnancy in a rural area of Gambia. Bullitene of WHO, 5, 635-643.

[18] Sachdev, H.P.S. (2001) Low birth weight in south Asia Division of Clinical Epidemiology, Department of Pediatrics. Maulana Azad Medical College, New Delhi.

[19] Siza, J.E. (2008) Risk factors associated with low birth weight of neonates among pregnant women attending a referral hospital in Northern Tanzania. Tanzania Journal of Health Research, 10, 1-8. 


\section{ABBREVIATIONS AND ACRONYMS}

AGA: Appropriate-for-Gestational-Age;

APH: Ante Partum Hemorrhage;

C/S: Caesarean Section;

FGR: Fetal Growth Retardation;
IUGR: Intrauterine Growth Retardation; LBW: Low Birth Weight;

LGA: Large-for-Gestational-Age;

MUAC: Mid-Upper Arm Circumference;

SGA: Small-for-Gestational Age. 